\title{
AS INTERFACES DO CUIDADO PELO OLHAR DA COMPLEXIDADE: UM ESTUDO COM UM GRUPO DE PÓS-GRADUANDOS DE ENFERMAGEM
}

The interfaces of the care from the look of the complexity: a study with a group of post-graduation students in nursing

Las interfaces del cuidado desde la visión de la complejidad: un estudio con un grupo de estudiantes de posgrado en enfermería

Alacoque Lorenzini Erdmann

Gabriela Marcelino
Keyla Cristiane do Nascimento

Juliana Aparecida Ribeiro

\section{Resumo}

0 cuidado é um processo interativo, dinâmico, solidário, técnico-científico, criativo, e caracteriza o trabalho da Enfermagem. Objetivou-se identificar o conceito de cuidado, os espaços onde o mesmo acontece, quem o pratica e quais as suas dimensões visualizadas por pós-graduandos em enfermagem de uma universidade federal. Trata-se de um estudo qualitativo, exploratóriodescritivo. A coleta de dados foi realizada em outubro e novembro de 2004, mediante entrevista com 15 discentes de pósgraduação em enfermagem. Os dados foram submetidos à análise de conteúdo temática, interpretados ao olhar do referencial da complexidade. Os resultados mostram os tipos de cuidado, espaços de cuidado, seres humanos envolvidos no cuidado e as dimensões de cuidado visualizadas pelos sujeitos do estudo. Estes resultados apontam para um cuidar ora mais criativo, com responsabilidade e mais autonomia, e ora mais caritativo e solidário. A complexidade do cuidado é evidenciada nas relações, interaç̃̃es e associações dos seres humanos, nos diversos espaços sociais.

Palavras-chave: Cuidado de Enfermagem. Formação de Conceito. Estudantes de Enfermagem.

\begin{abstract}
The care is an interactive, dynamic, solidary, technician-scientific, creative process, and characterizes the work of the Nursing. It was objectified to identify the care concept, the spaces where the same it happens, who practices it and which its dimensions, visualized by students of the post-graduation level in Nursing of a Federal University. It is about a qualitative study, exploratorydescriptive. The collection of data was realized in October and November of 2004, by means interview with 15 learning of after-graduation in nursing. The data had been submitted to the thematic content analysis, interpreted to the look of the complexity theory. The results show the types of care, spaces of care, involved human beings, and the dimensions of care visualized by the persons of the study. These results point a care however more creative, with responsibility and more autonomy, and however more charitable and solidarity. The complexity of the care is evidenced in the relations, interactions and associations of the human beings, in the diverse social spaces.
\end{abstract}

Keywords:

Nursing Care. Concept Formation. Students Nursing.

\section{Resumen}

El cuidado es un proceso interactivo, dinámico, solidario, tecnico-cientifico, creativo, y caracteriza el trabajo de la Enfermería. Se objetivó identificar el concepto del cuidado, los espacios donde sucede el mismo, quien lo practica y cuales son sus dimensiones visualizadas por estudiantes de los cursos de postgrado en enfermería de una universidad federal. Se trata de un estudio cualitativo, exploratorico-descrictivo. La recoleccion de datos fue realizada en octubre y noviembre de 2004, por medio de entrevista con 15 alumnos de postgrado en enfermería. Los datos fueron sometidos al análisis de contenido temático, interpretados desde la visión de la complejidad. Los resultados demuestran los tipos de cuidado, los espacios implicados del cuidado, los seres humanos y las dimensiones del cuidado visualizadas por los sujetos del estudio. Estos resultados señalan para un cuidado más creativo, con responsabilidad y más autonomía, y sin embargo caritativo y solidario. La complejidad del cuidado se evidencia en las relaciones, las interacciones y las asociaciones de los seres humanos, en los espacios sociales diversos.

Palabras clave:

Atención de Enfermería. Formación de Conceito.

Estudiantes de Enfermería. 


\section{INTRODUÇÃO}

0 cuidado tem se tornado um tema de destaque na Enfermagem e fora dela. 0 interesse por esse tema em nossa profissão reflete-se pelo número crescente de estudos encontrados na literatura nacional e internacional expressando-se também, através da realização de eventos e na criação de grupos de pesquisas, que têm como temática central o cuidado. A complexidade do cuidar parece estar cada vez mais evidente no ser e fazer do enfermeiro, levando-o à busca de uma prática que re-direciona a sua competência como um ser cuidador, envolvido com outros seres, situando-se no ambiente do cuidado, no cenário de múltiplas interações humanas.

A inquietação deste estudo surgiu a partir das discussões dos participantes do Grupo de Estudos e Pesquisas em Administração de Enfermagem e Saúde (GEPADES), em uma das suas temáticas de estudo: organização do cuidado pelo olhar da complexidade. 0 desafio de conhecer a complexidade do cuidar/ cuidado nos levou a retomar a leitura de estudos desenvolvidos por enfermeiras/os sobre a temática, que objetivaram contribuir com seus trabalhos para o embasamento da prática, educação e pesquisa em nossa área de conhecimento, bem como a explorar o olhar dos sujeitos envolvidos com o cuidado na enfermagem e saúde, tendo como foco os pósgraduandos de enfermagem de uma universidade. A partir das discussões realizadas, questiona-se: 0 que é 0 cuidado, qual o espaço em que se presencia o mesmo, quem o pratica e que dimensões são visualizadas. Assim, o presente estudo teve por objetivo identificar o conceito de cuidado, os espaços onde o mesmo acontece, quem o pratica e quais as suas dimensões, visualizadas por pósgraduandos em enfermagem de uma universidade.

A vinculação histórica da Enfermagem com o tema cuidado ocorre há muito tempo. Contudo, somente nas últimas décadas tem merecido a atenção de estudiosos e pesquisadores da área tais como Leininger ${ }^{1}$, Watson ${ }^{2}$, Silva ${ }^{3}$, entre outros, objetivando clarificar e compreender 0 significado deste conceito. 0 fenômeno do cuidado não é somente uma experiência subjetiva e material. Ele é também historicamente construído, sendo que circunstâncias particulares, ideologias e relações de poder criam as condições sob as quais o cuidado pode ocorrer, as formas que assumirá e as conseqüências que terá sobre aqueles que o realizam e o recebem 4 .

0 cuidado é considerado função primordial na sobrevivência de todo ser vivo, especialmente do ser humano.
Ser cuidado... cuidar de si próprio... cuidar... quem,.... Cuidar é e sempre será indispensável, não apenas à vida dos indivíduos mas a perenidade de todo grupo social ${ }^{5: 14}$.

Desse modo, o cuidado está presente antes mesmo da concepção do ser, e acompanha-o ao longo do seu processo existencial. 0 cuidado pode dar significado à vida e ordená-la ajudando o outro a crescer ${ }^{6}$. Um autor vai mais além, ao defender a dimensão ontológica do cuidado como um fenômeno constitutivo da existência humana, através do qual o ser humano estabelece uma relação essencial com 0 mundo ${ }^{7}$.

0 cuidado encontra-se como prioridade, anterior a qualquer atitude e situação do ser humano, o que significa dizer que ele se acha em toda atitude e situação de fato, significa reconhecer o cuidado como um modo de ser essencial ${ }^{7}$. 0 cuidado entra na natureza e constituição do ser humano. Se não receber cuidado desde o nascimento até a morte, o ser humano desestrutura, definha, perde sentido e morre. Esse cuidado reforça nossa identidade como pessoas, como seres de relações 8 .

Para um teólogo brasileiro, cuidar é mais que um ato; é uma atitude de ocupação, preocupação, responsabilização e de desenvolvimento afetivo com 0 outro. A atitude de cuidar gera atos que denotam preocupação com as pessoas, zelo pelas relações de amizade, interesse pelo bem-estar, desvelo para tornar o ambiente agradável e diligência para resolver os assuntos. Este teólogo ainda refere que o ser humano é único, livre e criativo, e como ele desenvolve sua habilidade de cuidar de si mesmo, dos outros, do planeta, tem interesse em detectar e decidir sobre o sentido de cuidar ${ }^{9}$.

$\mathrm{Na}$ Enfermagem, o cuidado começou a trilhar caminhos distintos desde a sua origem. Porém foi marcadamente através de Florence Nightingale que, dada a sua vocação para o cuidar, mostra o exercício do cuidado dentro de uma visão holística do ser humano e valoriza os fatores ambientais, entendendo como influentes no comportamento humano ${ }^{3}$. 0 modelo nightingaleano difundiu-se e influenciou, por anos, os cuidados realizados pela Enfermagem em muitos países, inclusive no Brasil. Posteriormente, outros referenciais emergiram e se consolidaram, colocando o cuidado como essência e/ou objeto central da Enfermagem.

No Brasil, uma Teoria de Enfermagem marca um fazer orientado pela expressão: "Gente que cuida de Gente"10. Outros estudos destacaram-se como os de Madeleine Leininger, que se dedicou a estudar sobre o cuidar e 0 
cuidado nas diferentes culturas desde a década de 70. Para Leininger, o cuidado é o foco único e domínio central da Enfermagem e é a contribuição especial da Enfermagem para a sociedade 1 . Em sua Teoria da Diversidade e Universalidade Cultural do Cuidado, verificou que as formas de as pessoas expressaremse e comportarem-se em relação ao cuidado estavam diretamente ligadas aos seus padrões culturais. Identificou construtos de cuidados e apresentou distinção entre cuidado no sentido genérico, cuidado popular e cuidado profissional em enfermagem.

Watson desenvolveu a Teoria do Cuidado Humano a partir de 1979, baseada na filosofia e ciência do cuidado de enfermagem. Ela define o cuidado como o ideal moral da Enfermagem, tendo como objetivo a proteção, o engrandecimento e a preservação da dignidade humana². Para a autora, o cuidado é considerado como holístico, pois promove humanismo, saúde e qualidade. E processo de cuidado humano requer intervenção, desejo, relacionamento e ações. A autora destaca os fatores de cuidado, os quais representam a estrutura para o estudo da Enfermagem, como ciência do cuidado.

Ao conceber os sistemas de cuidado de enfermagem orientada pelo olhar da complexidade, Erdmann ${ }^{11}$ explora o cuidado complexo, nas suas variadas dimensões, partindo da noção de que o cuidado está presente na vida humana, no seu processo vital desde o pré-conceber até 0 morrer 11:124. Para a autora, 0 ato/ação de cuidar pode ser aprendido, desaprendido, reaprendido e transmitido/partilhado, apesar de ser único, particular e singular, porém em momentos, espaços e movimentos presentes nas situações múltiplas do viver social.

$\mathrm{Na}$ Enfermagem, o cuidado faz parte de sua linguagem cotidiana. Caracteriza atividades/ações junto ao cliente. No ensino de enfermagem, sua concepção avança na busca de melhor compreensão do seu significado, pois prescrições de enfermagem como: "dar apoio psicológico", "confortar", "auxiliar" o cliente, "ficar junto", "esclarecer", "informar" e outras ainda carecem de saberes mais estruturados ${ }^{12}$.

0 cuidar, entendido como processo interativo, dinâmico, solidário, criativo, é parte importante do ser/ fazer da Enfermagem. Ele se sustenta em conhecimentos próprios, em tecnologia que depende em grande parte da ação humana, ou seja, de um trabalho realizado por seres humanos, cujos instrumentos centram-se nas habilidades, atitudes, modos de ser, e estruturas cognitivas do ser enfermeiro, como uma prática social importante para a sobrevivência e melhor viver humano.

A busca de subsídios com outros olhares sobre 0 cuidar, as noções sobre o cuidado e quais as suas dimensões podem ser estudadas pelo paradigma da complexidade, numa lógica que explora a diversidade, as ambigüidades, o pluralismo sobre o real, como possibilidade de ver novas configurações sobre 0 trabalho da enfermagem centrado no cuidado.

Entende-se que o trabalho da Enfermagem é um trabalho compartilhado, de ajuda mútua e em equipe. É um trabalho atento à segurança da vida realizado para ser livre de riscos, que caminha para uma melhor compreensão do ser e viver mais saudável, integrado à organização da natureza, no seu processo auto-ecoorganizador. É um trabalho que demanda técnica, equipamentos e materiais apropriados, e especialmente, muita sensibilidade humana. E ainda é um trabalho que promove a saúde, promove a vida. 0 exercício do cuidado nas suas múltiplas dimensões, promove 0 conforto, a segurança, o convívio com a doença, com o viver e 0 morrer, nos limites da compreensão da normalidade/ anormalidade da vida e da solidariedade humana.

\section{SITUANDO O REFERENCIAL DA COMPLEXIDADE COMO SUBSÍDIO PARA ANÁLISE DO CUIDADO}

A Complexidade é uma forma de compreender o mundo tendo a capacidade de integrar no real, as relações que sustentam a co-existência entre os seres no universo possibilitando o reconhecimento da ordem e da desordem; do uno e do diverso, da estabilidade e da mudança ${ }^{13}$. A complexidade tenta dialogar com as diversas dimensões que constituem os fenômenos e objetos, enfim, com a realidade.

A complexidade sustenta-se por sete princípios básicos, que são complementares e interdependentes ${ }^{14}$. Esses princípios possibilitam um olhar para a complexidade da organização do cuidado. Segundo Morin ${ }^{13-15}$, estes princípios podem ser descritos como se segue:

0 princípio sistêmico ou organizacional liga o conhecimento das partes ao conhecimento do todo, e o todo é igualmente mais e menos que a soma das partes, tendo algumas de suas qualidades inibidas pela organização do conjunto. Ressalta-se ainda que nada está isolado no universo e tudo está em relação. A organização é aquilo que constitui um sistema a partir de elementos diferentes. Ela é, ao mesmo tempo, uma unidade e uma multiplicidade.

0 princípio holográfico evidencia que não apenas a parte está no todo, como o todo está inscrito nas partes. Todavia isso não significa que a parte seja um reflexo puro e simples do todo, pois cada parte conserva sua singularidade e sua individualidade, mas de algum modo contém o todo. 
0 princípio da retroatividade permite 0 conhecimento dos processos auto-reguladores e rompe com o princípio da causalidade linear, no qual a causa age sobre o efeito e o efeito sobre a causa.

0 princípio da recursividade representa um circuito gerador em que os produtos e os efeitos são produtores e causadores daquilo que os produz. Um exemplo, a sociedade: ela é produzida pelas interações entre seres humanos e estas interações produzem um todo organizador que retroage sobre eles, para co-produzí-los como seres humanos; 0 que eles poderiam ser não o seriam se não dispusessem da instrução, da linguagem e da cultura.

0 princípio da autonomia/dependência (auto-ecoorganização) para o qual, os seres vivos são autônomos, mas a sua autonomia depende do meio exterior. Assim como eles têm necessidade de retirar energia, informação e organização de seu ambiente, sua autonomia é inseparável dessa dependência; por isto são concebidos como seres auto-eco-organizadores. No entendimento de Morin, a autonomia fundamenta-se na dependência do meio ambiente, passando a autonomia a ser um conceito complementar ao da dependência, embora Ihe seja também antagônico.

0 princípio dialógico permite assumir racionalmente a inseparabilidade de noções contraditórias (como ordem, desordem e organização), para conceber um mesmo fenômeno complexo, ou seja, ele une duas noções que tendem a se excluir reciprocamente, mas são indissociáveis em uma mesma realidade. Dialógico quer dizer que duas lógicas, dois princípios estão unidos sem que a dualidade perca-se nesta unidade. Com essa forma de pensar, Morin teve a idéia que ele chamou de unidualidade, quando afirma que o ser humano é um ser unidual, totalmente biológico e totalmente cultural, a um só tempo.

0 sétimo princípio, o da reintrodução do conhecimento em todo conhecimento, opera a restauração do sujeito e torna presente a problemática cognitiva central: da percepção à teoria científica, todo conhecimento é uma reconstrução, uma tradução por um espírito/cérebro numa cultura e num tempo determinados.

Os princípios descritos aliados às noções de ordem, desordem, contradição, e dificuldade lógica, formam o tecido da complexidade. Lembramos que complexus é o que está junto, é o tecido formado por diferentes fios que transformam numa só unidade, isto é, tudo se entrecruza, tudo se entrelaça para formar a unidade da Complexidade. Porém, a unidade do complexus que foi formada não destrói a variedade e a diversidade das complexidades que a teceram.

\section{ASPECTOS METODOLÓGICOS}

0 presente estudo é de natureza qualitativa e exploratório-descritiva, realizado nos meses de outubro e novembro de 2004, como parte do projeto de pesquisa: "Concepção de sistema organizacional de cuidados de enfermagem pelo olhar da complexidade das práticas dos serviços de saúde em ambiente mais saudável", aprovado pelo Comitê de Ética em Pesquisa da Instituição onde foi realizada a coleta de dados. Respeitou-se 0 Código de Ética Profissional, bem como a Resolução 196/ 96, do Conselho Nacional de Saúde ${ }^{16}$, que levam em conta princípios éticos básicos que devem orientar qualquer estudo que envolva seres humanos.

Os pós-graduandos em enfermagem de uma Universidade Federal receberam o convite para fazerem parte do estudo. Ao todo, 15 discentes participaram das entrevistas sobre o tema, mediante a concordância dos mesmos. Para a coleta de dados utilizou-se as seguintes questões norteadoras: 1) 0 que é cuidado para você? 2) Onde acontecem as relações de cuidado? 3) Quem está envolvido no cuidado? 4) Quais as dimensões de cuidado que você visualiza?

Os dados coletados foram submetidos à análise de conteúdo temática e interpretados pelos princípios da complexidade, através do agrupamento de respostas similares e de extração de uma síntese de cada questão. As idéias nucleadoras que emergiram deste estudo foram organizadas em quatro categorias: tipos de cuidado; espaços do cuidado, seres envolvidos no cuidado e dimensões de cuidado.

\section{ANÁLISE E INTERPRETAÇÃO DOS RESULTADOS}

\section{Tipos de cuidado}

Ao questionarmos os alunos da pós-graduação sobre "o que é o cuidado para você?", obtivemos as mais variadas respostas, as quais foram agrupadas em subcategorias, quais sejam: o cuidado como ação; como atividade de enfermagem; como subjetividade e como interação.

\section{O Cuidado como Ação}

0 cuidado da enfermagem é feito pela ação/ negociação/deliberação de seus cuidadores mediante necessidades levantadas, normalizadas ou não, ou de solicitações diversas ${ }^{17}$. Para os participantes do estudo, o cuidado pode ser visto como uma ação, pois dá idéia de movimento, de realização de uma atividade, de atuar junto a um agente, de executar algo para outro ser, de agir em benefício da saúde do outro, conforme evidenciado no seguinte discurso: 
Cuidar é estar com, tomar conta de, auxiliar e ajudar e prover atenção e cuidados a pessoas incapacitadas de se cuidarem por si mesmas. Ajudar estas pessoas momentaneamente incapacitadas a se tornarem novamente saudáveis e auto-suficientes (Amor).

Assim, para os pós-graduandos, cuidar traduz-se em uma atividade realizada para promover, manter ou recuperar a saúde. Seja através de atitudes como: estar com, tomar conta de, auxiliar a fazer, orientar e educar as pessoas impossibilitadas de praticar 0 autocuidado. Ou mesmo transmitir ao outro, sentimentos de amor, compreensão, ser solidário, tendo em vista que o cuidado subsidia o viver de toda a humanidade.

\section{O Cuidado como atividade de enfermagem}

0 cuidado é a essência, o ideal moral da Enfermagem, cuja finalidade é proteção, engrandecimento e preservação da dignidade humanat. As falas a seguir corroboram este pensamento:

No meu entendimento, o cuidado é a essência da Enfermagem, e envolve ações desenvolvidas em comum acordo entre duas pessoas, a que cuida e a que é cuidada. Estas ações podem ser de cunho físico, emocional, espiritual ou social (Ternura).

Cuidado (...), no contexto da Enfermagem, seria o objeto do cuidar, que é o objeto de estudo da Enfermagem. Cuidado é fortalecer a vida uns nos outros, é sustentar o movimento da vida para que ela seja plena junto com o ser. Cuidado é acolher o movimento do outro em direção à sua integridade. Cuidado é a percepção das múltiplas possibilidades do/no ser (Simpatia).

Nesse sentido, o cuidado é entendido como um processo e ele é o objeto de estudo ou foco de ação da Enfermagem. São ações desenvolvidas em comum acordo entre duas pessoas, podendo estas ser de cunho físico, emocional, espiritual ou social. É acolher o outro em todas as suas necessidades e etapas da sua vida.

\section{o Cuidado como subjetividade}

Refere-se ao que se evidencia na consciência e no inconsciente. No modelo vigente de cuidado à saúde, a subjetividade encontra pouco espaço, pois se valoriza mais o lado racional, objetivo, de resolução de problemas. Contudo, mesmo nas técnicas mais sofisticadas e na utilização da tecnologia, a subjetividade se faz presente.
A relação do cuidado mantém estreitos laços com a subjetividade humana, já que ela não é sujeito-objeto, mas acontece entre dois sujeitos.

Cuidado é zelo, preocupação e solicitude com a pessoa do outro (Gratidão).

É zelar, dar atenção, saber escutar, proteger, preocupar-se por si e pelos outro (Paixão).

Cuidado é toda e qualquer ação desenvolvida por um ser humano com a intenção de atender uma necessidade ou auxiliar o outro para que possa sentirse melhor. Porém, essas atitudes não precisam necessariamente ser realizadas de uma forma única ou por profissionais da saúde. Dessa maneira, fica evidente que o cuidado pode ser uma ação concreta, bem como um ato abstrato e subjetivo - zelo, presença, ouvir com atenção, na busca permanente de uma boa qualidade de vida.

\section{o Cuidado como interação}

0 cuidado é um processo de interações e associações entre os seres, sendo parte organizador do sistema de saúde, parte organizador dos sistemas de cuidados, co-organizando-se junto aos demais sistemas sociais ${ }^{17}$. De outro modo, a interação entre profissionais e clientes faz parte de todo o processo de cuidar $^{18}$. Pela ótica da Interação, que sugerem imagens de ligação entre elementos, informação e conexão, que demonstram ser fundamentais para desenvolver um cuidado interativo ou relacional, indicadas pela fala:

É um processo de inter-relações entre o cuidador e o que recebe o cuidado. São ações e atitudes imbuídas de conhecimentos acompanhadas de um certo grau de comportamento que propiciem estas inter-relações. Cuidado é um produto que ofertamos a alguém (Ternura).

Considerando o cuidado um bem caracterizado como um produto que ofertamos ao outro, nesse contexto caracteriza-se a necessidade de uma relação entre o cuidador e o ser cuidado, na qual se observa gestos e conhecimentos que facilitarão esta interação. 0 cuidado é um sistema que depende das interações entre os indivíduos, as quais dependem do cuidado, da atitude de facilitação, entreajuda e comunhão para 0 crescimento e sobrevida de ambos, dos domínios individuais e coletivos / sociais ${ }^{11}$. 
Dessa forma, depreende-se que o cuidado para os participantes do estudo compõe-se de toda e qualquer ação oferecida ao outro, desenvolvida em um processo de interação entre pessoas, podendo esta atividade ser praticada por algum profissional da Enfermagem, o qual faz do cuidado seu objeto de estudo; bem como ser acolhido por uma outra pessoa. Observa-se que tais ações ocorrem através de atitudes concretas e atos abstratos e subjetivos - zelo, presença, ouvir com atenção - com a finalidade de promover, manter ou recuperar a saúde e de buscar permanentemente uma boa qualidade de vida, tendo em vista que 0 cuidado subsidia o viver de toda a humanidade.

\section{Espaços de cuidado}

Analisando a concepção dos espaços sociais ou cenários de cuidado, onde ocorrem as relações de cuidado, percebemos que para os participantes do estudo, o cuidado pode ser praticado em qualquer espaço social, conforme os relatos apresentados a seguir:

Em todos os espaços em que o homem e a mulher relacionam-se com o outro, ou outros seres humanos, com animais, com as plantas, com os objetos, no trabalho, enfim, em toda a relação do ser humano com a natureza. Ou seja: em casa, no abrigo, no campo, no trabalho, em locais ou espaços que se propõem a abrigar, acolher, recuperar a saúde como, por exemplo: asilos, postos de saúde, hospitais, zoológicos, clínicas, etc (Carinho).

Qualquer espaço social é permeado de cuidado, ou seja, a familia, o trabalho, as instituições sociais e os serviços de saúde, escolas. Acredito que onde exista a presença do ser humano há relações de cuidado (Apego).

0 termo espaço ou cenário de cuidado propõe 0 conceito de extensão infinita, indicando que não existem limites para as pessoas expandirem ações de cuidado quando necessário. Há, ainda, discentes que relacionam o cuidado direcionando-o a um espaço interior, observando este cenário ou contexto pela ótica do Eu, no qual o indivíduo promove melhorias em seu próprio organismo e acaba por proporcionar, além do estar bem, um bom estado físico para o atendimento do outro, conforme os relatos a seguir:

Considero o primeiro espaço de cuidado, o espaço interno do indivíduo. 0 espaço que ele deve reconhecer em si mesmo e cuidar de si. 0 mais difíil e o passo mais importante para obtenção de resultados positivos.
0 espaço que não é interno, obviamente é externo e este é o segundo espaço. Depende do cuidar-se para então, se habilitar a cuidar do outro. Este espaço externo pode se dar em qualquer lugar, no domicílio, na escola, no espaço terapêutico de um serviço de saúde; espaço espiritual, social (Amor).

\section{(...) Espaços sociais é amplo. 0 próprio ser humano} já é um espaço social e se ele oferecer cuidado a si, ele é um espaço social. Então, espaço social é o contexto do momento do encontro dos envolvidos numa relação de cuidado (Simpatia).

Dessa forma, o cuidado se faz presente em todos os espaços sociais, sejam eles tanto habituais como 0 lar, o trabalho, a creche, quanto os ambientes onde as ações de cuidado acontecem com mais especificidades, tais como: hospitais, clínicas e asilos. Ou seja, em qualquer lugar onde seres humanos relacionam-se entre si e com a natureza/ambiente encontramos 0 contexto de cuidado. Para os discentes, o ser humano pode também ser considerado um espaço social, haja vista que o ser humano pode oferecer cuidado a si e/ ou a outro ser. Através das relações, interações e associações entre as pessoas, é que se observa 0 espaço ou cenário ou contexto nos quais ocorrem as ações de cuidado.

\section{Seres envolvidos no cuidado}

Ao questionarmos os participantes a respeito de quem está envolvido no cuidado, observou-se que os discentes incluíram nesta categoria todos os seres humanos e ainda instrumentos de suporte. Identificamos como categoria todos os "seres humanos" interessados em cuidar, tendo em vista que, para a maior parte dos participantes, qualquer ser está apto para praticar o cuidado. Eis um exemplo:

0 homem, a mulher, a criança, (o ser humano em todas as faixas etárias), os animais, plantas, a natureza em toda as suas dimensões: o campo, as flores, o ar, a água, a terra e suas diversas formações, os metais, etc. A humanidade e sociedades em suas dimensões de organização, construção, cultura, história, entre outras (Carinho).

A percepção dos seres envolvidos no cuidado voltase especialmente para o ser humano, pois compreende que todo o ser humano é um cuidador em potencial, como exemplo mostra a seguir:

0 cuidado estabelece-se entre as pessoas (o ser que cuida e o que é cuidado). Assim, o cuidado 
ocorre de todos para todos. (...) 0 cuidado se dá nos seres humanos, deles para eles e a partir deles através de suas interações entre si e com o ambiente. Sofre influência dos ambientes e da cultura (Saudade).

Estes seres humanos que cuidam, que estão envolvidos no cuidado, são seres que construíram um conhecimento técnico-científico para praticá-lo, conforme relatos de alguns participantes. Assim, nesta categoria, a prática do cuidado será exercida por profissionais. Estes tornaram-se indivíduos aptos para exercerem o processo de cuidado, que poderá beneficiar de algum modo as pessoas ao seu redor, proporcionando uma melhor qualidade de vida. 0 relato a seguir ilustra esta análise:

Os profissionais de saúde, da educação, das artes. Enfim, todos os demais profissionais, dependendo do objetivo que se pretende alcançar e das necessidades e das pessoas da própria comunidade ou sociedade (Otimismo).

Os pais, professores, médicos, enfermeiros, psicólogos, assistente social, governo (Paixão).

De acordo com os discentes, os sentidos, gestos, atos/ atitudes são instrumentos que contribuem para que as relações de cuidado aconteçam. Tudo aquilo que é perceptível pelos órgãos dos sentidos, e ainda as contribuições oriundas de relatos de experiências ou pesquisas anteriores relacionadas ao cuidar, caracterizamse como ferramentas em benefício dos seres que necessitam de cuidado. Os relatos dos participantes exemplifica estes aspectos:

0 receptor do cuidado, o cuidador e todo e qualquer material como espaço físico, ou outro artefato utilizado para prestar o cuidado. Pode ser um quarto ordenado (...), fotos, painéis com paisagens ou músicas, um gesto de acolhimento, chamar o outro pelo nome, olhar no olho de quem se está cuidando/escutando. Enfim, 0 que é necessário para uma boa relação interpessoal é componente do cuidado (Amizade).

... Objetos, conhecimento; os sentidos: tato, fala, audição, olfato, visão; amor, carinho, afeto; Instrumentos: materiais e equipamentos hospitalares, medicamentos (Ternura).

Os instrumentos utilizados como recurso para o cuidado podem ser, ainda, objetos mecânicos espećificos da área da saúde, e mesmo o conhecimento científico que cada ser humano possui, são considerados como sendo recursos empregados para alcançar o objetivo de melhorar a condição de vida das pessoas:

... Para cuidar precisamos do uso de instrumentos. Estes instrumentos podem ser, como no caso da Enfermagem, materiais e equipamentos hospitalares, ou podem ser inclusive, 0 conhecimento que cada ser humano possui e que o habilita e o qualifica para o cuidado ... (Saudade).

Assim, todos os seres humanos são capacitados para a prática do cuidado independente de cor, sexo ou idade. Basta que haja o cuidador e o ser cuidado para que esta relação de cuidado se estabeleça. É uma atividade que pode ser praticada em grupo ou individualmente, sendo necessário ter vontade e disponibilidade. Além do cuidado familiar e popular, estão envolvidos também nas ações de cuidado, todos os demais profissionais, independente da área de atuação, mas que almejam atender as necessidades do outro ou da comunidade. Para que o cuidado, aconteça são necessários instrumentos. Um deles é o conhecimento, que habilitará e qualificará o cuidador; além das demais ferramentas, sendo elas específicas, como as utilizadas pelos profissionais de saúde, tais como: materiais e equipamentos hospitalares de maior ou menor complexidade. Outros recursos presentes nas relações de cuidado são: os sentidos, os sentimentos, as atitudes, os gestos de acolhimento, o afeto, a música, entre outros. 0 cuidado envolve seres como sujeitos do processo, apoiados por instrumentos ou recursos que dão suporte ao ser e fazer em um contexto ou cenário de relações, interações e associações, como espaço físico e social da sua prática.

\section{Dimensões do cuidar}

Ao abordar as dimensões de cuidado visualizadas, os discentes focalizaram especialmente as questões ligadas ao envolvimento, tanto físico, quanto emocional. Destacam-se as seguintes dimensões de cuidado:

\section{Dimensão da humanização do cuidado}

Caracteriza-se pelo envolvimento existencial do cuidador com o ser cuidado, no qual ambos vivenciam e compartilham o encontro de cuidado, reconhecendo suas singularidades. 0 profissional de enfermagem para se envolver no cuidado demonstra a necessidade de construir e estabelecer uma relação baseada na confiança e no respeito mútuo. Neste encontro de 
cuidado mostram-se seres humanos que apresentam seu modo próprio de ser e estar no mundo, para os quais o amor e o respeito fazem parte de suas existências. Então, eles devem ser compreendidos como seres que têm suas próprias vivências e experiências, que os acompanham durante seu existir. Portanto, elas devem ser valorizadas e consideradas, para permitir a liberdade de escolha, durante o processo de cuidar.

Esta dimensão é priorizada pelos discentes, pois em nossa profissão trabalhamos com seres humanos. As dimensões sociais, familiares e de relações, de acordo com os participantes, encontram-se interligadas ao humano, gerando a promoção de uma relação harmônica entre os seres que cuidam e são cuidados:

Dimensões: familiar, social, de trabalho ... não dá para esquecer os ensinamentos de Horta: Enfermagem, é gente cuidando de gente (Apego).

\section{Dimensão da espacialidade de cuidado}

Configura-se por ser um ambiente, no qual existe uma pluralidade de elementos ou estrutura, e se desenvolve a Enfermagem como profissão, pela interação do ser humano com o ambiente.

Para que o cuidado se efetue, muitas vezes, há a necessidade do uso de recursos materiais ou equipamentos que dependem das condições econômicas presentes e do ambiente onde se encontram (Ternura).

Os seres humanos são seres auto-organizadores; são sistemas não só fechados, que protegem sua integralidade e sua identidade, mas também abertos ao seu ambiente, à natureza, de onde tiram energia, informação, organização. São, portanto, seres autoeco-organizadores. A organização viva é uma autoorganização que se produz e se reproduz, a partir de um patrimônio inserido nos genes, dependendo das condições externas para alimentar-se, autoreorganizar-se e auto-compor-se ${ }^{13}$.

\section{Dimensão da sistematização do cuidado}

A qual orienta as ações dos profissionais no planejamento e execução dos cuidados de enfermagem, fundamentando o seu agir na compreensão do ser humano como ser bio-psico-socioespiritual. É o método que confere a prática do saber e fazer técnico-científico adequado às necessidades de cada cliente. Inclui-se nesta subcategoria, as dimensões técnico-prática e teórico-epistemológica.

(...) dimensão técnico-prática, é a dimensão de como se faz; teórico-epistemológica, é a dimensão do planejamento ... (Simpatia).
0 cuidado para ser realizado necessita que o cuidador domine a técnica correta de realizá-lo, que tenha conhecimentos multidimensionais (Saudade).

0 cuidado, nas suas formas diferenciadas de relações pessoais e no que esta atividade se envolve/se desenvolve/ se compromete com o processo de viver, traduz-se em sistemas de cuidar com diversas possibilidades de aplicação/visualização e em múltiplas e variadas funções ou atitudes, pensando ora mais tecnicamente e ora mais empiricamente, ao acaso ${ }^{17}$.

\section{Dimensão ecológica de cuidado}

Configura-se no cuidado com a natureza para preservar o ambiente. Não apenas para proteger 0 ser humano, mas para manter um melhor equilíbrio ecológico, que promova uma relação mais harmoniosa entre o ser humano e a natureza. Dá idéia de proteção, interação, envolvimento e pertença.

(...) dimensões ecológicas. As dimensões são dimensões energéticas, e considero a grande possibilidade da Enfermagem, aprender cuidar nas várias dimensões. Sair [do] modelo biomédico (Amor).

\section{Dimensão cultural do cuidado}

É constituída por conceitos, significados, expressões, padrões, processos e formas estruturais de cuidar que são diferentes e similares entre todas as culturas do mundo. Portanto, cada cultura humana tem um conhecimento mais específico acerca de cuidado. Tanto o ser que cuida, como o que é cuidado são seres culturais. Assim, cuidar implica em uma atitude de respeito ao modo de viver de cada individuo, considerando suas crenças, seus valores, seus costumes, sua cultura.

... cultural, é a dimensão onde há a transformação do cuidado (Alegria).

0 cuidado, seja ele profissional ou praticado por familiares, acontece nos seres, a partir deles, para eles, através deles, coexistindo na natureza e por onde suas estruturas podem ser pensadas, pois se encontram na estrutura da organização da vida dos seres ${ }^{11}$.

As dimensões aqui apresentadas possibilitam práticas em esferas individuais e coletivas, buscando atender às necessidades de cada ser humano. Isto caracteriza as dimensões de cuidado como dinâmicas, interligadas e sem forma/extensão delimitadas, tornando-as mais como facilitadoras nas relações de cuidado, além de promover uma relação mais harmoniosa entre os seres humanos e a natureza. 


\section{CONSIDERAÇÕES FINAIS}

0 estudo mostra as diversas percepções das/os enfermeiras/os pós-graduandas/os acerca do cuidado, ao expressarem suas idéias das mais variadas formas, relacionando-as com as experiências vivenciadas em seu cotidiano de cuidado. As categorias e subcategorias encontradas apresentam-se interligadas e se complementam. Nelas, o cuidado configura-se como uma experiência de habilidades múltiplas, desde o lidar com outro ser humano, envolvendo o respeito por suas crenças, valores, sentimentos, indispensáveis, até uma relação mais harmoniosa, como o voltar-se a si mesmo, valorizando o seu espaço interior.

0 cuidar é existencial, relacional, contextual e complexo, e é construído entre os seres que cuidam e os seres que são cuidados. Ainda, como um cuidar que, ora é mais criativo, com mais responsabilidade e autonomia, e ora é mais caritativo e solidário. Ele é desenvolvido em qualquer relação do ser humano, nos mais diversos espaços sociais em prol da melhor qualidade de vida.

As dimensões de cuidado encontradas neste estudo foram: humanização, ecológico, cultural, sistematização do cuidado, de espacialidade, entre outras. Ao compreender as dimensões do processo de cuidar na Enfermagem, mostra-se o mundo do cuidado vivido pelas enfermeiras participantes do estudo, caracterizado por ser um ambiente com nuanças próprias, no qual o processo de cuidar apresenta-se multifacetado. Para os sujeitos do estudo, vivenciar o cuidado demanda compreensão do ser humano como ser único, capaz de compartilhar suas vivências e experiências no cotidiano de cuidado. 0 cuidado é um fenômeno existencial dos seres humanos e demais seres da natureza, fazendo-se presente na história da humanidade. Ele constitui-se do saber e fazer da Enfermagem, que valoriza e respeita a vida humana.

Reitera-se 0 entendimento de que 0 trabalho da enfermagem é compartilhado, de ajuda mútua e em equipe; é atento à segurança da vida, o mais livre de riscos, caminhando numa melhor compreensão do ser e viver mais saudável, integrado à organização da natureza, no seu processo auto-eco-organizador; e que é um trabalho que demanda técnica, equipamentos e materiais apropriados e, especialmente, de muita sensibilidade humana. Em síntese, é um trabalho que promove a saúde, promove a vida, previne os agravos à saúde. 0 exercício do cuidado nas suas múltiplas dimensões, promove o conforto, a segurança, o convívio com a doença ou a sua superação, com 0 viver e o morrer, nos limites da compreensão da normalidade da vida e da solidariedade humana. 0 cuidado complexo é plural e multifacetado, possibilitando avançar na compreensão do viver mais saudável.

\section{Referências}

1. Leininger MM. Caring: an essential human need. Detroit (USA):Slack; 1991.

2. Watson J. Enfermagem: ciência humana e cuidar uma teoria de enfermagem. Tradução de João Enes. Rio de Janeiro (R): Lusociência; 2002. 182p

3. Silva AL. Cuidado como momento de encontro e troca. Anais do $50^{\circ}$ Congresso Brasileiro de Enfermagem; 1998. p. 75 - 79.

4. Reverby S. A caring dilemma: womanhood and nursing in a historical perspective. Nurs Res 1987; 36: 5-11.

5. Collière MF. Promover a vida. Lisboa (PO): Sindicato dos Enfermeiros. Portugueses; 1989.

6. Mayeroff M. A arte de viver e servir ao próximo para servir a si mesmo. Rio de Janeiro (RJ): Record; 1971.

7. Heidegger M. Todos nós... ninguém. Tradução de Dulce Mara Cristelli. São Paulo (SP): Moraes; 1981.
8. Hayashi AAM. 0 cuidado de enfermagem no CTI: da ação/reflexão a conscientização. [dissertação mestrado]. Florianópolis (SC): Curso de Pós-Graduação em Enfermagem/ UFSC; 2000. 112 p.

9. Boff L. Saber cuidar: ética do humano, compaixão pela terra. Petrópolis (RJ): Vozes; 1999.

10. HortaWA. Processo deEnfermagem. São Paulo (SP):EPU/EDUSP; 1979. p. 99.

11. Erdmann AL. Sistema de cuidado de enfermagem. Pelotas (RS): Universitária/UFPel; 1996.

12. Maia ARR. Elementos e dimensões do cuidado na perspectiva de clientes ambulatoriais. Texto\&Contexto Enferm 1998; 7(2): 133-50.

13. Morin, E. Introdução ao pensamento complexo. $2^{\mathrm{a} e d}$. Lisboa (PO): Instituto Piaget; 1995.

14. Morin E. Os sete saberes necessários à educação do futuro. São Paulo (SP): Cortez; 2000. 
15. Morin E. A cabeça bem feita - repensar a reforma, reformar 0 pensamento. Rio de Janeiro (RJ): Bertrand Brasil; 1999.

16. Conselho Nacional de Saúde. Resolução nº196 de 10 de outubro de 1996. Diretrizes e normas regulamentadoras de pesquisa envolvendo seres humanos. Bioética 1996; 5(2): 13-44.

17. Erdmann AL. 0 sistema de cuidados de enfermagem: sua organização nas instituições de saúde. Texto\& Contexto Enferm 1998; 7(2): 52-69.

18. Castro ES, Mendes PW,Ferreira MA. A interação no cuidado: uma questão fundamental. Esc Anna Nery Rev Enferm 2005; 9(1): 39-45.

\section{Sobre as Autoras}

Alacoque Lorenzini Erdmann

Enfermeira, Doutora em Filosofia da Enfermagem, Professora Titular da UFSC e docente do Programa de PG-Enfermagem da UFSC. Pesquisadora CNPq. Coordenadora do GEPADES (Grupo de Estudos e Pesquisas em Administração de Enfermagem e Saúde). E-mail: alacoque@newsite.com.br

\section{Keyla Cristiane do Nascimento}

Mestranda em Enfermagem da Universidade Federal de Santa Catarina - UFSC. Bolsista CNPq/GEPADES. E-mail: keyla@nfr.ufsc.br

Gabriela Marcelino

Aluna da $4^{a}$ fase de Enfermagem da UFSC. Bolsista IC CNPq/GEPADES.

Juliana Aparecida Ribeiro

Aluna da $6^{\text {a }}$ fase de Enfermagem da UFSC. Bolsista PIBIC CNPq/ GEPADES. 